\title{
BENEFITS OF USE OF ACOUSTIC EMISSION IN SCRATCH TESTING
}

\author{
LukÁŠ VÁClaveK ${ }^{a, *}$, JAN TOMÁŠTíK ${ }^{b}$, Hana ChMelíčKovÁa $^{a}$, \\ RADIM ČTVRTLÍK ${ }^{c}$
}

a Joint Laboratory of Optics of Palacky University and Institute of Physics of the Czech Academy of Sciences, Faculty of Science, Palacky University, 17. listopadu 12, 77146 Olomouc, Czech Republic

${ }^{b}$ Institute of Physics of the Czech Academy of Sciences, Joint Laboratory of Optics of Palacky University and Institute of Physics AS CR, Olomouc, Czech Republic, 17. listopadu 50a, 77207 Olomouc, Czech Republic

${ }^{c}$ Regional Centre of Advanced Technologies and Materials, Joint Laboratory of Optics of Palacky University and Institute of Physics of the Czech Academy of Sciences, Faculty of Science, Palacky University, 17. listopadu 12, r7146 Olomouc, Czech Republic

* corresponding author: lukas .vaclavek@upol.cz

\begin{abstract}
Scratch test is regularly used for assessment of cohesive and adhesive strength of thin films and coatings. By default, its evaluation is based on analysis of depth-load-time record and microscopic observation of residual scratch groove. The visual analysis of the residual groove provides the most detailed description of the final damage of the surface (crack patterns, extent of plastic deformation, delamination, etc.), but it may be a time demanding approach. Although the continuous recording of indenter penetration depth and applied load offers instantaneous information about the performance of the tested material, it may not provide sufficient description of the sample's deformation behaviour. Therefore, other complementary techniques for description of the deformation response to scratch loading are desirable. Continuous recording of acoustic emissions (AE) generated during the test could be a possible solution. It is especially the ability of AE method to detect the very first and even subsurface failures of the material that is of the most importance and otherwise inaccessible by standardly used techniques. What is more, it is a non-destructive and real-time method. In principle, $\mathrm{AE}$ method can be beneficially employed for a wide range of materials explored via scratch test. The strength of the $\mathrm{AE}$ analysis of the nano/micro scratch test will be demonstrated on various types of materials including optical thin films, durable metal and hard ceramic films as well as bulk laser cladding. Selected phenomena and features of the use of AE during scratch testing will be presented, including effect of scratch load on character of $\mathrm{AE}$ records (burst vs. continuous) for $\mathrm{TiO}_{2}$ on glass, subsurface damage of $\mathrm{SiC}$ films on silicon and selective failure of hard carbide phase embedded in a metal matrix in case of laser re-melted layers.
\end{abstract}

KEYwORDS: Acoustic emission, laser cladding, scratch test, thin films.

\section{INTRODUCTION}

\subsection{SCRATCH TEST}

The scratch test is a standard tribo-mechanical test for determination of cohesive-adhesive properties of coated materials. The test is based on lateral movement of the loaded tip across the sample surface, while different types of damage and/or wear can be simulated depending on the experimental setup (tip geometry, load, loading rate, environment, etc.). In most cases, a progressive loading with a chosen maximum is used. Nevertheless, abrupt loading can also be employed for example in wear test, where constant sub-critical load is applied several times over the same track [1]. In fact, various scenarios could take place under the action of the generated pressure field based on the nature of the film/substrate properties. Depending on the actual loading conditions, the material deforms beneath the moving indenter and various types of failures could occur including brittle film cracking, tensile cracking, ploughing, and film delamination according to mechanical properties and adhesion of the studied film-substrate system [2].

The scratch test applicability for evaluation of layered materials durability is given by the reliable detection of the onset of their failures, either in films, substrate or film/substrate interface. Standard methods of scratch test evaluation are based on accurate identification of the critical loads representing onsets of those failures by visual observation of residual scratch groove using a microscope and/or analysis of load-displacement-time data. Specific failure modes including different crack types along with plastic deformation are usually observable using modern microscopic techniques with sufficient resolution. However, there are film-substrate systems, where initial cracking is not detectable by microscopic techniques or depth-change data. The examples may be cracking at the film-substrate interface or substrate cracking 

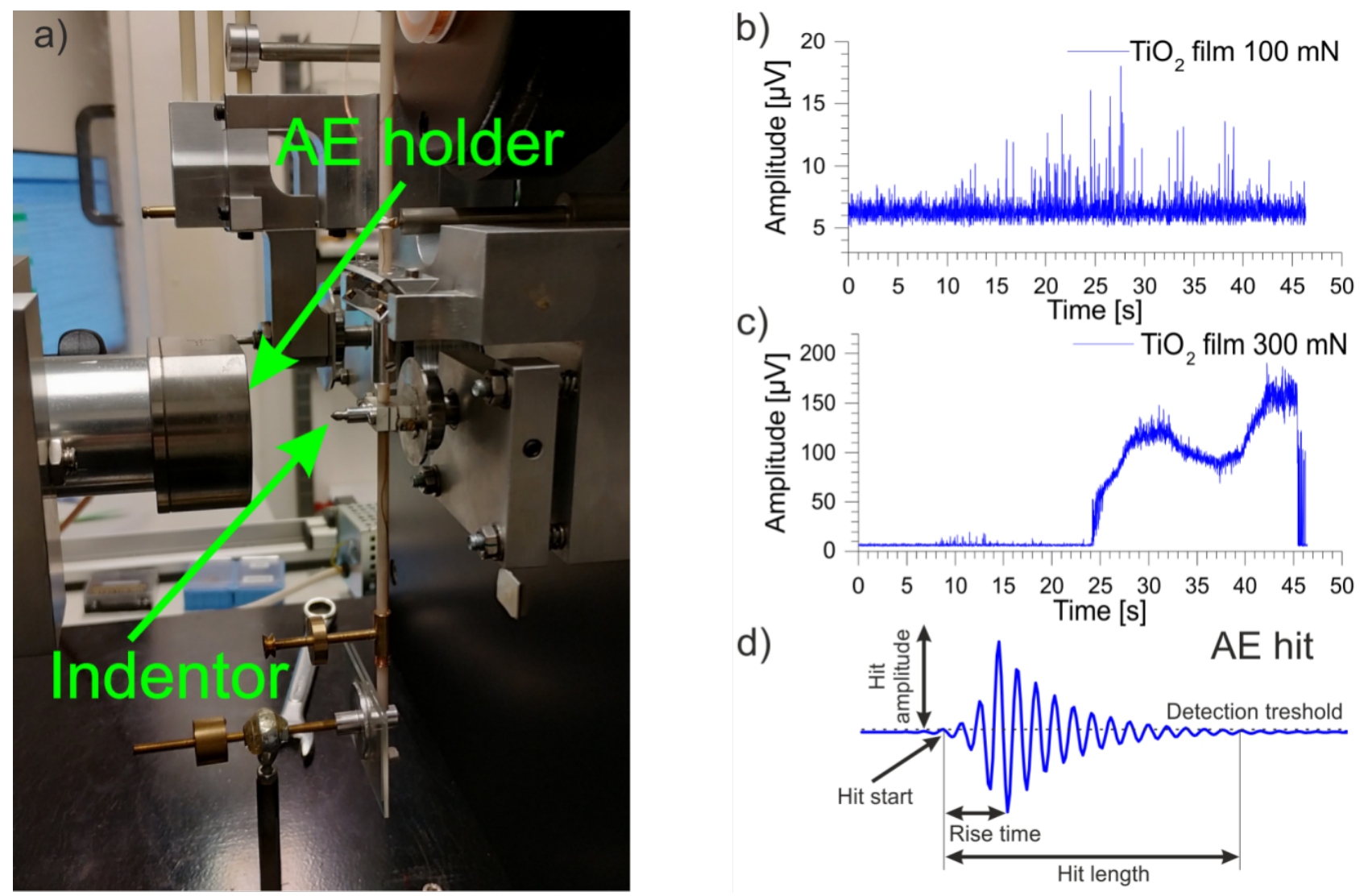

c)

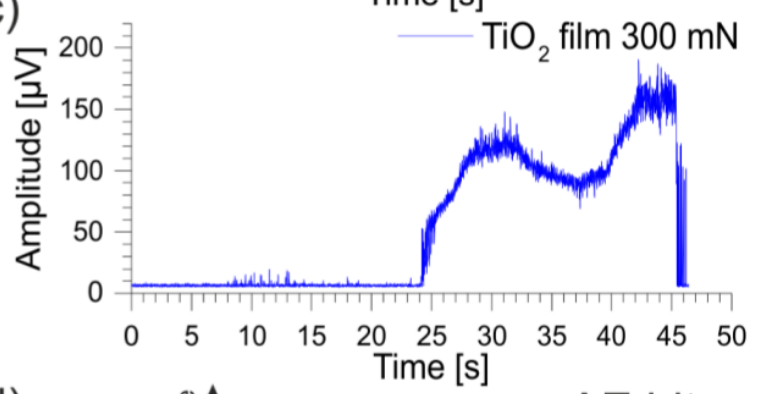

d)

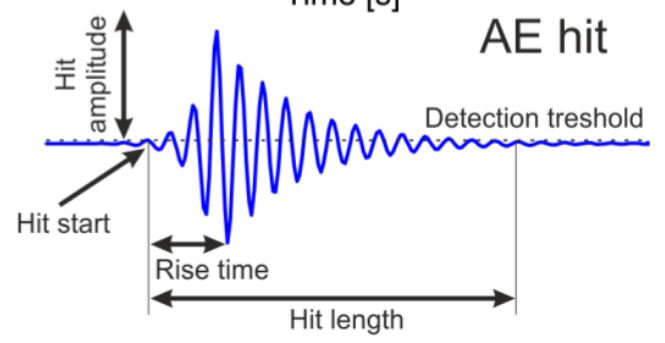

Figure 1. Acoustic emission: a) AE holder implemented in the NanoTest system, b) burst AE envelope, c) continuous $\mathrm{AE}$ envelope d) AE hit waveform; b) and c) represents data from thin optical film on glass substrate.

\begin{tabular}{|c|c|c|c|c|c|c|}
\hline Sample & Film & $\begin{array}{l}\text { Deposition } \\
\text { techniques }\end{array}$ & Substrate & $\begin{array}{c}\text { Spherical tip } \\
\text { radius [um] }\end{array}$ & $\begin{array}{l}\text { Max. Load } \\
{[\mathrm{mN}]}\end{array}$ & $\begin{array}{c}\text { Thickness } \\
\text { [nm] }\end{array}$ \\
\hline SiC film & $\mathrm{SiC}$ & $\begin{array}{l}\text { Magnetron } \\
\text { sputtering }\end{array}$ & Si wafer & 5 & 300 and 500 & 2500 \\
\hline Cr film & $\mathrm{Cr}$ & $\begin{array}{l}\text { Magnetron } \\
\text { sputtering }\end{array}$ & $\begin{array}{c}\text { steel } \\
\text { (CSN } 16 \text { 720) }\end{array}$ & 5 and 10 & 500 & 250 \\
\hline TiO2 film & $\mathrm{TiO} 2$ & $\begin{array}{l}\text { Magnetron } \\
\text { sputtering }\end{array}$ & glass & 5 & 100 and 300 & 285 \\
\hline $\begin{array}{c}\text { Laser } \\
\text { cladding }\end{array}$ & $\begin{array}{l}\text { Remelted iron } \\
\text { based powder }\end{array}$ & $\begin{array}{l}\text { Laser } \\
\text { cladding }\end{array}$ & $\begin{array}{c}\text { steel } \\
(\mathrm{CSN} 12 \text { 050) }\end{array}$ & 10 & 500 & $\sim 6 \times 10^{6}$ \\
\hline
\end{tabular}

TABLE 1. Overview of tested samples and experimental conditions used in this study.

under the opaque film 3]. Therefore, new reliable methods are desirable. Acoustic emission can be an appropriate solution for such cases [4, 5].

\subsection{Acoustic emission}

At macro scale, acoustic emission (AE) is established as a standard non-destructive method in defectoscopy for the interfacial and cohesion failure detection, localization and evaluation of material defects and cracks of large-scaled objects [6, 7]. The energy levels released during macromechanical tests are many times higher than those released from the highly localized process volumes in nanomechanical and nanotribological tests [8]. Therefore, AE sensors have to feature an optimized design that is vital to achieve sufficient sen- sitivity and reliability for applications at nano/micro scale. Besides, the standard AE approaches and protocols have to be also adopted for specifics of nano/micro mechanical tests.

The AE method principle is detection of the elastic waves generated by a sudden release of energy from a localized source in the material [9, 10]. Energy release occurs when the material undergoes changes in its internal structure, for example due to cracking or plastic deformation arising from temperature gradients or external mechanical forces. Typically, the piezoelectric material-based sensors attached to the sample are used for detection of AE signals (Fig. 1 1a). These sensors are capable of detecting very small events with low AE signal amplitude. Traditionally, the acoustic 
emission record is represented by the so-called AE envelope. It is a time-compressed signal that provides a quick overview about $\mathrm{AE}$ activity during the test and can be categorized into two types: i) burst emissions and ii) continuous emissions. A burst emission is a discrete packet of waves associated with a single event, whereas continuous emission is considered as a superposition of many small events, see Fig. 1 b and 1.

The AE envelope mainly gives information about the onset of the first cracks or an apparent change in failure mode. However, more throughout analysis of individual AE events can also be performed based on evaluation of the high-frequency sampled AE signal with sub-microsecond resolution. The discrete AE events are then represented by so called "AE hits" and can be further analysed in terms of their energy, and time and frequency parameters, see Fig. 1 1 .

In this paper, the high frequency AE monitoring was used during scratch testing of different thin films, coatings and bulk in order to demonstrate the benefits and features of AE technique. In the following sections the effect of scratch load on AE character for optical TiO2 films on glass, subsurface damage of SiC films on silicon and selective failure of hard carbide phase embedded in a metal matrix in case of laser re-melted layers are shown.

\section{EXPERIMENTAL SETTINGS}

Diverse types of samples with different mechanical properties were explored using scratch test. Specifically, a laser cladding on steel, magnetron sputtered Cr film on steel, $\mathrm{SiC}$ film on $\mathrm{Si}$ and $\mathrm{TiO}_{2}$ on glass substrate, see Table1. In all cases, samples were fixed using a low temperature wax on the special AE holder installed in the NanoTest instrument (MicroMaterials, Wales), where all the nano/micro mechanical tests were performed, see Fig. 1 1 . Scratch tests were performed with a fully calibrated NanoTest instrument at room temperature with diamond spherical indenters. Tips with end radius of 5 and $10 \mu \mathrm{m}$ were used in order to generate different stress fields. During the tests, the normal force was linearly increased up to pre-set maximum (see Table 1) over the scratch track of $450 \mathrm{\mu m}$. Acoustic emission was recorded during the test using the ZEDO system (Dakel, Czech Republic). This AE system consists of a dedicated sample holder with a piezoelectric sensor and an in-built preamplifier, a recording unit and a controlling software. AE signals were obtained with 16 bits sampling resolution, sampling frequency of $10 \mathrm{MHz}$ and frequency bandwidth from $30 \mathrm{kHz}$ to $2 \mathrm{MHz}$. The scratch test evaluation was performed using a combination of three independent approaches: post process evaluation of residual scratch groove using microscopic techniques, the depth-change record analysis, and the acoustic emission envelope signal analysis. Measured samples along with used experimental details are listed in the Table 1.
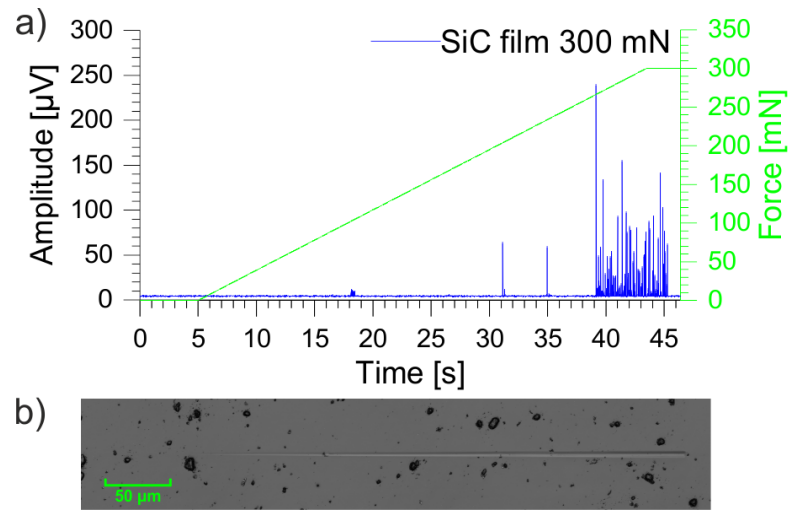

Figure 2. Scratch test performed up to $300 \mathrm{mN}$ on $\mathrm{SiC}$ thin film: a) AE envelope b) residual scratch groove.

\section{Results And Discussion}

\section{1. $\mathrm{TIO}_{2}$ THIN FILM - BURST VS. CONTINuOUs AE}

AE envelope recorded during scratch testing on transparent $\mathrm{TiO}_{2}$ film on transparent substrate is shown in Fig. 1. The TiO2 film with thickness of $285 \mathrm{~nm}$ on glass was tested up to 100 and $300 \mathrm{mN}$. It can be clearly seen that with the increase of normal load the character of AE signal also changes. A scratch test of the sample with a maximum load of $100 \mathrm{mN}$ leads to the burst AE, induced by film cracking and breakage, see Fig. 1 p. Increase of maximum load to $300 \mathrm{mN}$ changes the character of the AE envelope to a continuous one, as shown in Fig. 1. This change is caused by scratching through the film directly to glass substrate. Cracking of the glass is then responsible for strong continuous AE signal.

\subsection{Sub-Surface CRACKING of SiC COATING ON SI}

Sub-surface damage is a typical effect that might lead to a substantial overestimation of the tribolog$\mathrm{ical} /$ mechanical durability of the film/substrate system if not considered. Despite the possibilities of up-to-date microscopic approaches, they are limited to detection of surface damage. In other words, very limited options for detection of the sub-surface damage are available. The effect of sub-surface damage on scratch test evaluation and beneficial use of $\mathrm{AE}$ method can be presented for amorphous $\mathrm{SiC}$ film magnetron sputtered on Si substrate. A series of scratch tests with a maximum load of $300 \mathrm{mN}$ and $500 \mathrm{mN}$ were performed, similarly to [5].

High resolution visual observation with the laser scanning confocal microscope combined with the analysis of depth-load-time record does not reveal any damage in the film tested up to $300 \mathrm{mN}$ (Fig. 2) and only faint cracking beyond $460 \mathrm{mN}$ (Fig. 3) suggesting high durability of the films Nevertheless, AE signal clearly reveals extensive subsurface cracking taking place already from $270 \mathrm{mN}$. Subsurface crack- 


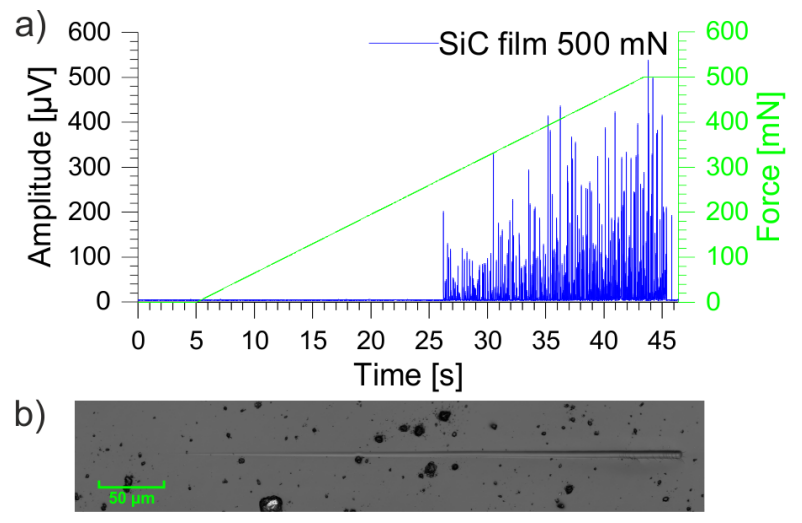

FiguRE 3. Scratch test performed up to $500 \mathrm{mN}$ on $\mathrm{SiC}$ thin film: a) $\mathrm{AE}$ envelope b) residual scratch groove.

ing was directly confirmed on similar samples using the SEM-FIB cross-sectioning [5]. When we compare these values to the visually identified critical load for the first surface distinguishable cracks, then we can conclude that microscopic analysis overestimates the critical load by $70 \%$.

\subsection{EFFECT OF INDENTER RADIUS ON AE SIGNAL FOR CR THIN FILMS ON STEEL}

In general, acoustic emission has been known to be a very effective method for brittle materials. Nevertheless, it can be used also for systems of metal films deposited on steel substrates. Figure 4 shows an AE envelope recorded during a scratch test on Cr film sputtered on steel substrate up to $500 \mathrm{mN}$. Since scratch tests on non-coated steel surface did not produce any detectable AE signal it can be concluded, that $\mathrm{AE}$ is produced solely by the $\mathrm{Cr}$ film cracking. Microscopic analysis of the residual scratch grooves also supports that i) Cr film damage perfectly corresponds to the AE envelope as can be seen from Fig. 4 and ii) no signs of cracking were observed on the uncoated steel substrate (steel CSN 16 720).

Scratch test is a very sensitive method to the used experimental conditions [11, 12] and direct comparison between various studies have to be made with care. It is apparent that use of indenter with a different radius substantially changes the stress field beneath the moving indenter [13, 14. Figure 4,also compares AE envelopes for the $\mathrm{Cr}$ film on steel substrate tested at the same experimental conditions with $5 \mu \mathrm{m}$ and $10 \mu \mathrm{m}$ sphere. It can be clearly seen that distinguishable AE signal undoubtedly above the noise level was detected only for the test made with the indenter with smaller radius of $5 \mu \mathrm{m}$.

\subsection{LASER CLADDING}

Although, scratch test has been used primarily for adhesion/cohesion testing of thin films, it may provide useful information on mechanical behaviour of thick coatings deposited by laser cladding technology. In fact, these coatings with thickness up to several

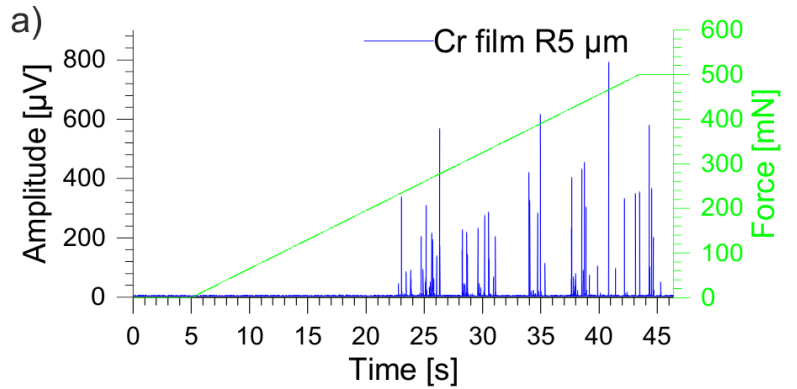

b)

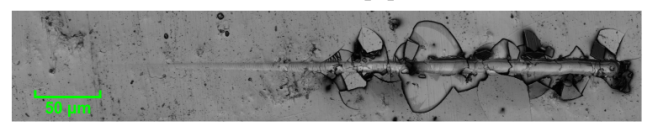

C)

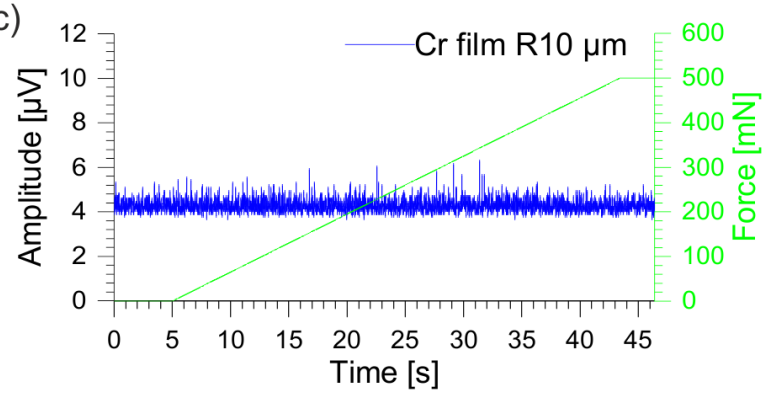

Figure 4. Cr thin film: a) AE envelope b) corresponding residual scratch groove made during the scratch test up to $500 \mathrm{mN}$ with a sphere of radius of $5 \mu \mathrm{m}$, and c) $\mathrm{AE}$ envelope for the test performed up to $500 \mathrm{mN}$ with a sphere of radius of $10 \mu \mathrm{m}$.

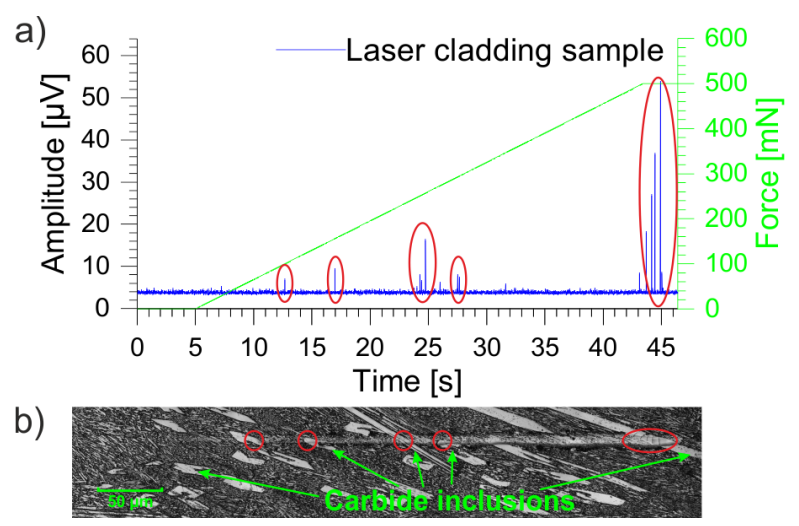

Figure 5. Laser cladding sample: a) AE envelope graph and b) surface image with marked areas of cracks (bright spots represent carbide inclusions)

millimeters, prepared by laser melting of micrometer size metal powder, may be considered as bulk. Here we report on a scratch test performed on a coating deposited from an iron-based mixture with $4.1 \%$ of C, $32.0 \%$ of $\mathrm{Cr}, 0.5 \%$ of $\mathrm{Si}$ and $0.8 \%$ of $\mathrm{Mn}$ on carbon steel substrate (steel CSN 12 050) using a fiber-coupled diode laser type LDM 3000-100 (wavelength 900-1070 nm). Although the depth changes records did not exhibit any dramatic fluctuations originating from structural changes, a distinct AE signal was detected during the test. Subsequent microscopic observation of the residual groove revealed well defined microstructure with carbide inclusions. Comparison of the AE signal and microscopic images clearly points 
out extensive cracking inside the carbide inclusions (see Fig. 5). This means that AE method is able to reflect microstructural features of the investigated material.

\section{Conclusions}

Detection of acoustic emissions generated during the nano/micro-mechanical/tribological tests provides valuable information about deformation and failure mechanisms in the tested materials. It was demonstrated that application of the acoustic emission detection system during nano/micro scratch test proved to be very beneficial as it brings a capability to detect events previously undetectable by the standard scratch test evaluation approaches. Acoustic emission can provide information about deformation and crack initiation in subsurface areas or film-substrate interfaces, which is undetectable neither by microscopic evaluation of residual scratch groove or from depth-change record data. The acoustic emission signal, recorded simultaneously during the scratch test, can be clearly assigned to a certain point of residual scratch groove, hence to the initiation of specific failure mode. Such analysis might reveal valuable information about deformation processes and their dynamics in both bulk as well as layered materials. Described AE method can be easily adapted to other local deformation or destructive methods like nanoindentation, pillar compression or cantilever bending tests.

\section{ACKNOWLEDGEMENTS}

The authors gratefully acknowledge the support by the Project TH03020245 of the Technology Agency of the Czech Republic and the Operational Programme Research, Development and Education, Projects Nos. CZ.02.1.01/0.0/0.0/17_049/0008422 and CZ.02.1.01/0.0/0.0/16_019/0000754 of the Ministry of Education, Youth and Sports of the Czech Republic. This work was also supported by the project IGA_PrF_2019_008 of Palacky University.

\section{REFERENCES}

[1] L. Šimurka, R. Čtvrtlík, J. Tomaštík, et al. Mechanical and optical properties of $\mathrm{SiO} 2$ thin films deposited on glass. Chemical Papers 72(9):2143-2151, 2018. DOI:10.1007/s11696-018-0420-z

[2] S. Bull. Failure modes in scratch adhesion testing. Surface and Coatings Technology 50(1):25-32, 1991. DOI:10.1016/0257-8972(91)90188-3

[3] J. Tomaštík, R. Čtvrtlík, M. Dráb, J. Maňák. On the importance of combined scratch/acoustic emission test evaluation: $\mathrm{SiC}$ and $\mathrm{SiCN}$ thin films case study. Coatings 8(5):196, 2018. DOI:10.3390/coatings8050196

[4] R. Čtvrtlík, J. Tomaštík, L. Václavek, et al. High-resolution acoustic emission monitoring in nanomechanics. JOM 71(10):3358-3367, 2019. DOI:10.1007/s11837-019-03700-8.
[5] J. Tomaštík, R. Čtvrtlík, T. Ingr, et al. Effect of nitrogen doping and temperature on mechanical durability of silicon carbide thin films. Scientific Reports 8(1), 2018. DOI:10.1038/s41598-018-28704-3

[6] C. Grosse, M. Ohtsu (eds.). Acoustic Emission Testing. Springer Science \& Business Media, 2008. DOI:10.1007/978-3-540-69972-9

[7] W. Sikorski (ed.). Acoustic Emission: Research and Applications. InTech, 2013. DOI:10.5772/50270

[8] S. Gholizadeh, Z. Leman, B. Baharudin. A review of the application of acoustic emission technique in engineering. Structural Engineering and Mechanics 54(6):1075-1095, 2015. DOI:10.12989/sem.2015.54.6.1075

[9] D. F. Bahr, W. W. Gerberich. Relationships between acoustic emission signals and physical phenomena during indentation. Journal of Materials Research 13(4):1065-1074, 1998. DOI:10.1557/jmr.1998.0148

[10] N. I. Tymiak, A. Daugela, T. J. Wyrobek, O. L. Warren. Highly localized acoustic emission monitoring of nanoscale indentation contacts. Journal of Materials Research 18(4):784-796, 2003. DOI:10.1557/jmr.2003.0109.

[11] P. Steinmann, H. Hintermann. Adhesion of TiC and $\mathrm{Ti}$ (C, N) coatings on steel. Journal of Vacuum Science \& Technology A: Vacuum, Surfaces, and Films 3(6):2394-2400, 1985. DOI:10.1116/1.572845

[12] B. Beake, A. Ogwu, T. Wagner. Influence of experimental factors and film thickness on the measured critical load in the nanoscratch test. Materials Science and Engineering: A 423(1-2):70-73, 2006. DOI:10.1016/j.msea.2005.09.121.

[13] N. Randall, G. Favaro, C. Frankel. The effect of intrinsic parameters on the critical load as measured with the scratch test method. Surface and Coatings Technology 137(2-3):146-151, 2001. DOI:10.1016/S0257-8972(00)01097-5

[14] J. Tomaštík, R. Čtvrtlík. Effect of intrinsic parameters on evaluation of critical loads in nanoscratch test. Proceedings of 30th Danubia Adria Symposium on Advances in Experimental Mechanics 2013. 